\title{
SUSTENTABILIDADE EMPRESARIAL COM FOCO SOCIAL EM UMA INDÚSTRIA DO SEGMENTO QUÍMICO CORPORATE SUSTAINABILITY WITH SOCIAL FOCUS ON A CHEMICAL SEGMENT INDUSTRY
}

\section{Cristiane Froehlich ${ }^{1}$}

\section{Resumo}

Este artigo tem como objetivo verificar as ações que contemplam o pilar social da sustentabilidade empresarial em uma indústria do segmento químico, localizada na Região do Vale do Rio dos Sinos, no Estado do Rio Grande do Sul. Essa pesquisa classifica-se como descritiva e com método de estudo de caso qualitativo. Os dados foram coletados por meio de cinco entrevistas semiestruturadas e documentos que foram analisados por meio da análise de conteúdo qualitativa. Os principais resultados mostram que a empresa investe em ações sociais que contribuem para a sustentabilidade empresarial. Essas ações são coordenadas por três áreas da organização: a) Fundação, foco no público interno e comunidades; b) Desenvolvimento Organizacional, foco no público interno; c) Tecnologia, foco no desenvolvimento de produtos denominados de ecossociais.

Palavras-chave: Pilar Social. Sustentabilidade. Segmento Químico.

\begin{abstract}
This article aims to verify the actions that contemplate the social pillar of business sustainability in an industry of the chemical segment, located in the Vale do Rio dos Sinos Region, in the State of Rio Grande do Sul. This research is classified in descriptive and study qualitative case. The data were collected through five semi-structured interviews and documents that were analyzed using qualitative content analysis. The main results show that the company invests in social actions that contribute to corporate sustainability. These actions are coordinated by three areas of the organization: a) Foundation, focus on the internal public and communities; b) Organizational Development, focusing on the internal public; c) Technology, focusing on the development of products called eco-socials.
\end{abstract}

Keywords: Social Pillar. Sustainability. Chemical Segment.

${ }^{1}$ Doutora em Administração pela Universidade do Vale do Rio dos Sinos (UNISINOS). Docente e Pesquisadora do Programa de Pós-Graduação em Administração da Universidade Feevale, Novo Hamburgo, Rio Grande do Sul, Brasil. E-mail: froehlich.cristiane@gmail.com 


\section{INTRODUÇÃO}

No contexto organizacional a reputação das empresas tem se tornado preponderante para o reconhecimento junto à sociedade. As transformações do ambiente apontam para o alinhamento das estratégias organizacionais com os stakeholders. (ALIGLERI; ALIGLERI; KRUGLIANSKAS, 2009; JORDÃO et al., 2009; FERNANDES; FONSECA; CUNHA, 2018).

Nesse sentido, verifica-se que as partes interessadas expressam suas preocupações com as ações sociais, exigem maior envolvimento das empresas nas soluções dos problemas e questionam os papeis das organizações na sociedade. Com isso, os consumidores começaram a demandar a produção de produtos e serviços consistentes com os valores relacionados com a questão da sustentabilidade. (PORTER; KRAMER, 2006; AMORIM, 2009; ALIGLERI; ALIGLERI; KRUGLIANSKAS, 2009).

Apesar do aumento crescente dos investimentos sociais corporativos no Brasil, é possível afirmar que a comunidade empresarial está dividida em dois segmentos. No primeiro estão as empresas que privilegiam as atividades diretamente ligadas à rentabilidade dos seus negócios. Estas empresas acreditam que cumprem a sua função social gerando empregos e pagando impostos, e elas percebem as iniciativas no campo social como responsabilidade do Estado, ou seja, do governo. Em oposição a este modelo, surge o paradigma adotado por empresas que identificam a questão social como uma função estratégica, onde "trabalhar para construir capital social e natural se enquadra na razão da organização.” (MELO NETO; FROES, 2004, p. 44).

Contudo, existem empresas que deixam a desejar na adoção de estratégias de sustentabilidade em suas atividades operacionais. Isso reflete no acúmulo de problemas e conflitos com os seus públicos interno (dirigentes e empregados) e externo (clientes, fornecedores e comunidades). Desse modo, as unidades são administradas com o único foco centrado na sustentabilidade do negócio, em outras palavras, visão imediatista do lucro, redução dos custos, produção em escala, reengenharia de processos com perda de empregos e automação. (MELO NETO; FROES, 2011).

O desempenho social inadequado e a falta de políticas podem trazer sérias implicações para as empresas, acarretando prejuízos materiais e morais de modo a aumentar os custos e perder oportunidades de mercado. Sendo assim, analisar as ações sociais de uma empresa oportuniza avaliar o desempenho sustentável para a sociedade. (AMORIM, 2009; ALIGLERI; ALIGLERI; KRUGLIANSKAS, 2009).

Vale ressaltar que a "gestão responsável e sustentável construída pelas pessoas e a forma como a organização interage com seus colaboradores pode impactar positivamente no comprometimento, empenho e satisfação." (ALIGLERI; ALIGLERI; KRUGLIANSKAS, 2009, p. 116). Isso corrobora com Aspinall, Cukier \& Doberstein (2011), os autores defendem que as empresas socialmente sustentáveis se preocupam com práticas diárias que melhoram as condições de vida, saúde e segurança, bem-estar, educação, lazer, salário digno e convívio social. $\mathrm{O}$ ambiente de trabalho e o modo como às pessoas são tratadas, tanto o público interno como o externo, influenciam no crescimento e na sustentabilidade da organização.

Diante do exposto, verifica-se que a problemática central considera a necessidade de compreender as ações que estão sendo desenvolvidas no contexto empresarial que contemplam o pilar social da sustentabilidade. Esse estudo visa responder a seguinte questão de pesquisa: Quais são as ações sociais que constituem a sustentabilidade empresarial em uma organização do segmento químico?

Para esse estudo buscou-se uma organização que fosse representativa, seguindo os seguintes critérios de seleção: a) a sustentabilidade deveria ser uma estratégia da organização; b) a sustentabilidade deveria estar inserida na missão, visão e valores organizacionais; c) possuir publicações sobre a sustentabilidade nos balanços sociais e relatórios de sustentabilidade. Com base nesses critérios, selecionou-se uma empresa do segmento químico, localizada na Região do Vale do Rio dos Sinos, no Estado do Rio Grande do Sul. 
A empresa destacou-se entre as demais da região tendo em vista o seu reconhecimento no ramo de atuação; a sustentabilidade está incluída na missão, visão e nos valores organizacionais; pelo desenvolvimento de patentes de produtos e de processos, que se caracterizam como inovações orientadas para sustentabilidade; possui publicações sobre sustentabilidade nos balanços sociais; é reconhecida no mercado pelas práticas de responsabilidade social empresarial; e publicou o primeiro relatório de sustentabilidade (modeloGlobal Reporting Initiative) em 2015, referente ao ano de 2014.

O estudo teve como objetivo verificar as ações que contemplam o pilar social da sustentabilidade empresarial em uma empresa do segmento químico. Os objetivos específicos norteadores da pesquisa foram: a) descrever as ações sociais da empresa; b) identificar as áreas responsáveis pela condução dessas ações sociais. Para atender aos objetivos, essa pesquisa classifica-se em descritiva e estudo de caso qualitativo. Os dados foram coletados por meio de cinco entrevistas semiestruturadas com as pessoas indicadas pela direção da empresa. Também foram investigados documentos internos. Os dados foram analisados por meio da análise de conteúdo qualitativa.

As contribuições do estudo estão relacionadas com a apresentação das ações sociais que contribuem para a sustentabilidade empresarial no contexto estudado. Ainda, o estudo mostra as áreas responsáveis pela coordenação dessas ações sociais da sustentabilidade.

A seguir apresenta-se o referencial teórico, que contempla os conceitos de desenvolvimento sustentável e sustentabilidade empresarial, e o pilar social da sustentabilidade.

\section{SUSTENTABILIDADE EMPRESARIAL}

A sustentabilidade pode ser entendida como a manutenção de um sistema ao longo do tempo, período que depende da adaptabilidade, diversidade, resiliência, equidade e interação entre os pilares econômico, ambiental, social e cultural. (FILHO et al., 2014). Está integrada ao conceito de desenvolvimento sustentável, que é definido como um processo de mudança no qual os recursos naturais, os investimentos, a orientação do desenvolvimento tecnológico e as mudanças institucionais estão em harmonia e reforçam o potencial do presente e do futuro, com a finalidade de atender às necessidades e as aspirações humanas. (BRUNDTLAND, 1987; GLADWIN; KRAUSE; KENNELY, 1995; BOSSEL, 1999; LAFFERTY; MEADWCROFT, 2000).

Pode ser constatado, que no contexto de comissões internacionais e governos, utiliza-se a expressão “desenvolvimento sustentável", e no contexto empresarial, é utilizada a expressão "sustentabilidade empresarial". Sendo assim, a sustentabilidade empresarial contribui para o desenvolvimento sustentável em longo prazo devido à ênfase de ações continuadas. (FROEHLICH, 2014).

Searcy (2012) enfatiza que a sustentabilidade empresarial é considerada um problema complexo e que não há abordagens que se apliquem universalmente. Isso ocorre porque as empresas enfrentam diferentes demandas das partes interessadas. Diante disso, as empresas devem desenvolver suas políticas e ações de sustentabilidade conforme os seus contextos locais.

Para Galpin \& Whittington (2012) as empresas parecem estar tomando iniciativas de sustentabilidade por uma ampla variedade de razões. Algumas estão vinculando essas iniciativas a estratégias de marca e imagem, enquanto outras veem a sustentabilidade como um elemento-chave em suas tentativas de cortar custos ou se diferenciar dos concorrentes. Além da construção da marca, muitas empresas também estão integrando a sustentabilidade em suas declarações de valor.

A sustentabilidade empresarial significa adotar estratégias de negócios e atividades que atendam às necessidades das empresas e dos seus stakeholders, em outras palavras, visa gerar lucro para o acionista, sem desqualificar os aspectos socioambientais. (ELKINGTON, 1997; VAN MARREWIJK, 2003; BELL; MORSE, 2008; ANDINO, 2011; WILLARD, 2014, PHILIPPI JR; SAMPAIO; 
FERNANDES, 2017). Desse modo, o conceito de sustentabilidade induz a um novo modelo de gestão de negócios que leva em conta, no processo de tomada de decisão, além dos eventos socioeconômicos, os socioambientais. (PHILLIP JR; SAMPAIO; FERNANDES, 2017).

Diante disso, os compromissos das empresas com a sustentabilidade exigem uma abordagem estratégica para que seja integrada nas estratégias e processos de negócios. Para isso, Engert, Rauter \& Yoon (2015) ressaltam a relevância do envolvimento das partes interessadas para gerar impactos positivos e obter benefícios em longo prazo. Mozaffar, Serafeim \& Yoon (2015) fizeram um estudo para mensurar os resultados considerados materiais e imateriais das questões de sustentabilidade que podem auxiliar as empresas nas tomadas de decisões sobre investimentos em sustentabilidade.

Linnenluecke \& Griffiths (2016) apontam que o caminho para a adoção de princípios de sustentabilidade leva à adoção de uma cultura organizacional orientada à sustentabilidade. Os resultados das pesquisas conduzidas pelos autores mostraram que os funcionários de diferentes tipos de culturas enfatizaram diversos aspectos na busca da sustentabilidade corporativa, variando de um foco no desenvolvimento interno da equipe, eficiência, proteção ambiental ou engajamento das partes interessadas.

A publicação de relatórios corporativos de sustentabilidade, a integração da sustentabilidade nas medidas de avaliação de desempenho dos funcionários e treinamentos, pode fornecer um contexto propício para mudanças nos valores e crenças dos funcionários. (LINNENLUECKE; GRIFFITHS, 2016).

A abordagem da sustentabilidade corporativa evoluiu ao longo dos últimos anos, de forma independente e em ritmo diferente nos países. A teoria da sustentabilidade abrange os três pilares denominados de: econômico, ambiental e social, que devem ser incorporados nas estratégias organizacionais. Estes três pilares moldaram o novo paradigma de sustentabilidade corporativa. (CHRISTOFI; CHRISTOFI; SISAYE, 2012).

Mais importante que os conceitos dos termos desenvolvimento sustentável e sustentabilidade é a compreensão de quais são, efetivamente, os objetivos que estes conceitos expressam. Embora as definições sobre desenvolvimento sustentável sejam consideradas imprecisas e abrangentes, é possível reconhecer uma linha comum que envolve a ideia de eficiência econômica, equilíbrio do meio ambiente e equidade social. (LAFFERTY; MEADWCROFT, 2000; FROEHLICH, 2014).

\subsection{O Pilar Social da Sustentabilidade Empresarial}

Tanto em países desenvolvidos, como no Brasil, surgem discussões sobre os papeis das empresas como agentes nos processos de desenvolvimentos de ações sociais para promoção da sustentabilidade.

Diante disso, torna-se fundamental que as organizações assumam não só o papel de produtoras de bens e serviços, como também de responsáveis pelo bem-estar de seus funcionários e da sociedade. Segundo Faria \& Pereira (2009, p.3), a demanda da responsabilidade socioambiental organizacional "surgiu após a percepção da necessidade de todos os setores atuarem em prol do desenvolvimento sustentável. A premissa [...] é o fato de não existir empresa sem sociedade e meio ambiente".

Ainda segundo os autores, para que as empresas mantenham suas operações, as mesmas devem ser capazes de encontrar o alinhamento entre os interesses econômicos próprios, as necessidades ambientais e as demandas sociais, a fim de atender aos desejos e necessidades da sociedade na qual estão inseridas. Algumas empresas já perceberam que a valorização das pessoas está entre os principais fatores que se refletem diretamente em seu sucesso como forma de se obter vantagem competitiva. (PORTER; KRAMER, 2006).

No contexto empresarial, antes da disseminação da ideia de sustentabilidade, na questão social, exercia-se a responsabilidade social corporativa que surgiu no início do século $\mathrm{XX}$, com a prática filantrópica, cujo objetivo era prestar serviços de assistência social, fazer doações para entidades de caridade, recolher donativos como forma de assistência aos mais pobres. (CARROL, 1991). No âmbito 
interno das organizações, as ações de responsabilidade social se restringiam ao pagamento de salários dignos, à garantia de condições satisfatórias de trabalho para todos os empregados e à concessão de benefícios estabelecidos em lei. (TENÓRIO, 2004; YUNUS, 2008; MELO NETO; FROES, 2011).

A responsabilidade social empresarial concentrou-se em dois períodos distintos, o primeiro compreendeu o início do século XX até a década de 1950; o segundo representou a abordagem contemporânea, estendendo-se da década de 1950 até os dias atuais, incorporando a discussão da sustentabilidade. Conforme Tenório (2004) até a década de 1950, a resolução das questões sociais eram atividades exclusivas do Estado, uma visão que incorporava os princípios do liberalismo. No entanto, verificou-se o agravamento de questões como qualidade de vida, meio ambiente e condições de trabalho, gerando pressões para resolução desses problemas.

Em relação aos governos, eles devem fazer a sua parte, mas não sozinhos. Ao analisar o papel das organizações sociais e outras organizações sem fins lucrativos, muitas delas criadas a partir das preocupações com os problemas sociais e ambientais, foram e são úteis para auxiliar as pessoas que se encontravam ou se encontram em situações desesperadoras e contribuem para salvar vidas depois de inundações e maremotos, por exemplo. A partir dos investimentos sociais privados, o exercício da responsabilidade social assumiu a forma de projetos sociais. (YUNUS, 2008).

Vale ressaltar as diferenças entre os conceitos, a responsabilidade social se refere à valorização do ambiente onde as pessoas estão inseridas nas organizações, suas opiniões e anseios, respeitos pelos direitos e individualidade de cada um, contribuindo para o progresso das empresas e para melhorias nos relacionamentos com os stakeholders. A sustentabilidade social possui um conceito mais amplo e compreende um conjunto de elementos e características focados na sobrevivência e bem estar de uma sociedade visando à preservação do bem comum. (FROEHLICH, 2014).

Com o surgimento do paradigma da sustentabilidade, a responsabilidade corporativa evoluiu para uma nova dimensão, ou seja, uma ação de estratégia social de natureza sustentável. Isso significa que "o principal foco de atuação social da empresa é o desenvolvimento local e/ou regional e, a promoção da inclusão social, digital, política, cultural e econômica.” (MELO NETO; FROES, 2011, p. 86), apresentadas no Quadro 1.

Quadro 1 - O desenvolvimento da Sustentabilidade Social

\begin{tabular}{|c|l|}
\hline $\begin{array}{c}\text { Formas de } \\
\text { inclusão }\end{array}$ & \multicolumn{1}{c|}{ Significados } \\
\hline Social & $\begin{array}{l}\text { Significa integrar as pessoas que vivem na comunidade a estreitar laços entre os membros } \\
\text { dessas comunidades, promover e incentivar ações de solidariedade e de mudanças de } \\
\text { comportamento no âmbito local e/ou regional. Internamente, os principais desafios são a } \\
\text { integração do corpo funcional e a educação para um novo ambiente de trabalho. }\end{array}$ \\
\hline Digital & $\begin{array}{l}\text { Compreende ações de difusão dos conhecimentos sobre o uso e aplicações de equipamentos } \\
\text { e programas de computadores, domínio de algumas tecnologias de informática básicas e } \\
\text { promoção do acesso gratuito à internet. }\end{array}$ \\
\hline $\begin{array}{c}\text { Política e } \\
\text { cívica }\end{array}$ & $\begin{array}{l}\text { Representa o incentivo à população no exercício da cidadania e o aumento da autoestima dos } \\
\text { habitantes do local. }\end{array}$ \\
\hline
\end{tabular}




\begin{tabular}{|c|l|}
\hline Econômica & $\begin{array}{l}\text { Ocorre através da geração de empregos e renda, incentivos e apoio à criação de pequenas } \\
\text { empresas locais e o fomento do empreendedorismo de base comunitária. }\end{array}$ \\
\hline Cultural & $\begin{array}{l}\text { Ocorre através do apoio às manifestações culturais e participação quanto à preservação } \\
\text { do patrimônio físico, histórico e paisagístico, em alguns casos de inestimável valor, } \\
\text { assim como do incentivo à formação de desenvolvimentos locais nas áreas de atuação } \\
\text { requeridas pelas necessidades do meio ambiente e pelas empresas. }\end{array}$ \\
\hline
\end{tabular}

Fonte: Adaptado de Melo Neto \& Froes (2011).

A partir do Quadro 1, verifica-se que o desenvolvimento do pilar social da sustentabilidade permite diversas formas de inclusão, no âmbito interno e externo da empresa. Ao promover esses modos de inclusão, junto aos seus diversos públicos-alvo, a empresa assume o seu papel de agente indutor no contexto da sustentabilidade.

Sachs (1993) ressalta que o pilar social busca um novo estilo de vida adequado ao momento presente e ao futuro. Visa o desenvolvimento econômico aliado a uma melhoria significativa na qualidade de vida da população mundial, ou seja, maior equidade na distribuição de renda, melhorias na saúde, na educação, nas oportunidades de emprego, etc.

O pilar social contempla as ações e as condições que afetam todos os membros da sociedade, como por exemplo, a pobreza, a violência, a injustiça, a educação, a saúde pública, o trabalho e os direitos humanos. (CATALISA, 2003; WERBACH, 2010). Esse pilar trata da consolidação de processos que promovem a equidade na distribuição dos bens e da renda para melhorar substancialmente os direitos e condições de amplas massas da população e reduzir as distâncias entre os padrões de vida das pessoas. (BARBIERI; CAJAZEIRA, 2009).

Os conceitos acima apresentados sobre o pilar social contemplam a sociedade como um todo. Coral (2002) reforça que esse pilar da sustentabilidade no contexto empresarial incorpora a questão da responsabilidade social, o compromisso com o desenvolvimento dos recursos humanos, a promoção e a participação em projetos de cunho social e o suporte para o crescimento da comunidade local e/ou regional. Nesse sentido, Littlejohns \& Smith (2013) ressaltam que esse pilar enfatiza a preocupação não apenas com os colaboradores, como também, com a população, a partir do momento em que traz em seus princípios norteadores a sustentabilidade social, agrega estratégias desenvolvidas para a promoção da saúde, inclusão social e capacitação individual.

De modo geral, os aspectos geralmente contemplados no pilar social no contexto empresarial são: segurança no trabalho, saúde preventiva, ambiente limpo e seguro, ambiente de trabalho que favoreça a produtividade, adequação às leis trabalhistas, campanhas e programas socioambientais, formação de pessoas e lideranças, benefícios adicionais aos estabelecidos por lei, incentivo à educação dos funcionários, realização de programas de integração entre empresa e comunidade, etc. (FROEHLICH, 2014).

Vale ressaltar que algumas organizações que "se proclamam agentes do desenvolvimento sustentável, não são sustentáveis na administração da sua força de trabalho e no desenvolvimento dos seus fornecedores e parceiros, pois não promovem a sustentabilidade de modo integral." (MELO NETO; FROES, 2011, p.43). Geralmente apresentam os seguintes comportamentos como, por exemplo, de acordo com os mesmos autores:

- Negam-se a desenvolver ações sociais sustentáveis com o foco nos seus empregados, ou seja, remuneram mal, não adotam critérios justos de remuneração e promoção, alimentam competições na busca de resultados máximos, pregam lealdades e praticam arbitrariedades, criam escalas desumanas 
de trabalho, obrigam os empregados a regimes de horas extras abusivos, limitam-se aos benefícios obrigados por lei e deixam de reconhecer e valorizar seus melhores talentos;

- Suas ações sociais sustentáveis internas são voltadas para a inclusão social de minorias, que na realidade, são segmentos sociais majoritários da população brasileira (mulheres, pessoas de cor negra, descendentes de indígenas, pessoas acima de 50 anos);

- Pouco ou nada fazem em benefício dos empregados e clientes em situação de riscos financeiros (negociação de dívidas, parcelamentos, alertas sobre excesso de endividamento) e social (acidentados, portadores de doenças crônicas, vítimas de perdas na família);

- Ignoram as mudanças em curso nas comunidades vizinhas de suas unidades e perdem a oportunidade de se converter em agentes do desenvolvimento sustentável local;

- Limitam-se a lançar produtos "verdes", sem, no entanto, contribuir para a educação em favor de uma vida melhor para seus clientes e de uma economia mais humana e solidária;

- Buscam apenas economizar o consumo de recursos naturais, mas não investem na renovação desses recursos;

- Não adaptam os seus modelos de negócios às novas transformações socioambientais do mundo atual;

- Apenas dialogam com membros e entidades da sociedade sem, no entanto, contribuir efetivamente para o desenvolvimento de uma sociedade sustentável.

Para constatar a promoção de ações sociais para sustentabilidade no contexto empresarial, procede-se à análise estratégica da atuação da empresa no relacionamento com os seus clientes, fornecedores, demais parceiros comerciais e comunidades. Diante disso, ressalta-se que os impactos sociais das ações adotadas não são independentes dos impactos econômicos, uma vez que a criação de empregos, o aumento da atividade produtiva, o acesso a melhores produtos e serviços, assim como a melhora da posição do país no cenário internacional têm repercussão no nível de vida da população. (SEBASTIAN, 2000). Sierdovski, Stefano \& Andrade (2018) dizem que para o colaborador se sentir honrado em falar da organização em que trabalha e à medida que pode realizar suas metas e objetivos, o mesmo passa a externalizar seus sentimentos e afetos para terceiros quanto ao apreço e consideração que tem pela organização onde trabalha.

Christofi, Christofi \& Sisaye (2012) reforçam que a responsabilidade social da sustentabilidade é mais difícil de avaliar até embora custe à sociedade tanto quanto, se não mais, quanto à poluição ambiental edegradação de recursos.

\section{PROCEDIMENTOS METODOLÓGICOS}

Para esta pesquisa foi realizado um estudo de caso qualitativo e descritivo. A opção por esse tipo de pesquisa teve como principal justificativa a ideia de mergulhar na compreensão das práticas da organização e suas implicações. (YIN, 2005). A vantagem da pesquisa qualitativa é que busca compreender situações nas suas particularidades local e temporal, a partir das expressões dos sujeitos e de suas respectivas atividades. Ainda, contempla o esclarecimento de um fenômeno que não pode ser mensurado em quantidade. (FLICK, 2004).

O presente estudo de caso busca verificar as ações sociais que contribuem para sustentabilidade empresarial. Nesse contexto, buscou-se uma organização que fosse representativa, seguindo os seguintes critérios de seleção: a) a sustentabilidade deveria ser uma estratégia deliberada da organização; b) a sustentabilidade deveria estar inserida na missão, visão e valores organizacionais; c) possuir publicações sobre sustentabilidade nos balanços sociais. Com base nesses critérios, selecionou-se uma empresa do segmento químico, cuja matriz localiza-se no sul do Brasil, na Região do Vale do Rio dos Sinos, no Rio Grande do Sul. 
Para coleta dos dados foram realizadas análises de documentos e entrevistas. Os seguintes documentos foram consultados: a) Relatório de Sustentabilidade; b) Livro Institucional da empresa; c) portal da Internet da empresa. O roteiro de entrevista foi adaptado de Froehlich (2014) e contemplou as seguintes questões: Como a empresa define a sustentabilidade social? Fale sobre a estrutura da área de sustentabilidade social da empresa. A sustentabilidade é de responsabilidade de algum departamento específico? Descreva a trajetória da inserção da sustentabilidade social na organização. Quais são as ações sociais praticadas pela empresa? Quais as motivações da empresa para atuar com ações de sustentabilidade social? Como os resultados da sustentabilidade social são mensurados e divulgados?

As entrevistas em profundidade foram realizadas com cinco pessoas indicadas pela direção da empresa. Essas pessoas ocupam cargos de liderança nas áreas envolvidas com a questão social da sustentabilidade. O número de entrevistados mostrou-se suficiente para a coleta de dados tendo em vista o critério de saturação. Para preservar a identidade dos entrevistados, eles foram denominados: Entrevistado 1 (E1), Entrevistado 2 (E2) e assim sucessivamente, de forma aleatória. O Quadro 2 resume o perfil dos entrevistados.

Quadro 2 - Perfil dos Entrevistados

\begin{tabular}{|c|c|c|}
\hline Cargo/Função & $\begin{array}{l}\text { Tempo de } \\
\text { Empresa }\end{array}$ & Grau de Instrução \\
\hline $\begin{array}{l}\text { Coordenadora de Projetos } \\
\text { de Tecnologia }\end{array}$ & 9 anos & $\begin{array}{l}\text { Graduação em Química. MBA em Gestão Empresarial e } \\
\text { Projetos. }\end{array}$ \\
\hline $\begin{array}{l}\text { Coordenador de Saúde, } \\
\text { Segurança e Meio Ambiente }\end{array}$ & 5 anos & $\begin{array}{l}\text { Graduação em Engenharia Ambiental e em Engenharia } \\
\text { de Segurança no Trabalho. MBA Internacional em Gestão } \\
\text { Ambiental. }\end{array}$ \\
\hline Coordenadora da Fundação & 5 anos & $\begin{array}{l}\text { Graduação em Serviço Social. Especialização em } \\
\text { Administração e Planejamento de Recursos Humanos. } \\
\text { Mestrado em Educação. }\end{array}$ \\
\hline $\begin{array}{l}\text { Consultora de } \\
\text { Desenvolvimento }\end{array}$ & 8 anos & Graduação em Administração. MBA em Estratégia e Inovação. \\
\hline $\begin{array}{l}\text { Diretor de Desenvolvimento } \\
\text { Organizacional }\end{array}$ & 5 anos & $\begin{array}{l}\text { Graduação em Contábeis. MBA em Gestão de Negócios. MBA } \\
\text { em Tecnologia Social. }\end{array}$ \\
\hline
\end{tabular}

Fonte: Elaboração Própria.

Os dados coletados foram analisados por meio da análise de conteúdo qualitativa. Essa técnica representa a categorização de elementos centrais com base no referencial teórico previamente levantado. A categorização é uma técnica eficaz para a organização e a redução dos dados, por meio do agrupamento das informações em um número limitado de categorias. (BARDIN, 2010).

Primeiramente foram analisados os dados obtidos por meio dos documentos, que após a codificação permitiram a compreensão da origem da sustentabilidade e a identificação das ações sociais. Essa análise foi realizada antes da coleta de dados por meio de entrevistas, e permitiu a autora conhecimentos sobre as ações sociais praticadas pela empresa.

Em seguida, foram agendadas as entrevistas com as pessoas indicadas, visando aprimorar os dados identificados nos documentos. Cada entrevista teve duração média de 45 minutos, foram gravadas a partir da permissão dos entrevistados. Posteriormente, os conteúdos gravados foram transcritos em um documento "Word". Os dados coletados dos documentos e entrevistas foram codificados e confrontados e a análise permitiu a resolução da questão de pesquisa proposta. 


\section{APRESENTAÇÃO DA EMPRESA E DAS AÇÕES SOCIAISDO PILAR DA SUSTENTABILIDADE EMPRESARIAL}

A empresa foi fundada na década de 1940, caracteriza-se como uma empresa familiar, de capital fechado. A matriz situa-se no Estado do Rio Grande do Sul. Possui plantas industriais situadas no Brasil e na América Latina.

A empresa passou a utilizar o termo sustentabilidade nas publicações e em seus balanços sociais a partir de 2006. Antes disso, utilizava a palavra ecoeficiência. (ENTREVISTADO 3). Conforme o entrevistado 4, "a visão socialmente responsável que permeava a empresa desde a sua fundação, passou a ser considerada dentro do conceito de sustentabilidade em 2006". Assim, as iniciativas sustentáveis ganharam reforços, planejadas de acordo com os três pilares da sustentabilidade: econômico, ambiental e social.

A partir dos relatos dos entrevistados, pode-se afirmar que a empresa apresenta iniciativas de sustentabilidade que foram integradas nas estratégias corporativas. (GALPIN; WHITTINGTON, 2012; ENGERT; RAUTER; YOON, 2015).

As ações sociais da sustentabilidade são conduzidas por três áreas da empresa: a) Fundação que realiza ações para os públicos interno e externo; b) área de Desenvolvimento Organizacional (DO) que realiza ações para o público interno; c)área de tecnologia, que desenvolve tecnologias de produto com foco em ganhos sociais. Sendo assim, as ações sociais são planejadas e gerenciadas por essas três áreas, apresentadas a seguir.

A Fundação teve início na década de 1980, idealizada pelo empreendedor e fundador. Atua alinhada às estratégias da sua mantenedora ao lado da unidade matriz. A Fundação é responsável por direcionar e gerir o investimento social da empresa e desenvolver ações socialmente responsáveis para o público interno e para as comunidades onde está inserida, respeitando e valorizando a cultura local. (RELATÓRIO DE SUSTENTABILIDADE, 2018). Nesse sentido, Searcy (2012) enfatiza que as empresas devem desenvolver suas políticas e ações de sustentabilidade conforme os seus contextos locais.

A missão da Fundação consiste em ser o braço social da organização para promoção do desenvolvimento social sustentável dos funcionários, suas famílias e das comunidades onde atua. (ENTREVISTADO 2). Desse modo, segundo o entrevistado 5, "o foco da Fundação é para a educação, por meio de processos sócios educativos para dar condições de empregabilidade e de profissionalização aos participantes para enfrentar o mercado". A prestação de contas é auditada pela Deloitte Touche. (ENTREVISTADO 3).

O ano de 2007 marcou o início de uma nova fase da Fundação, foi reconhecida como uma Organização da Sociedade Civil de Interesse Público (OSCIP), definida pela Lei 9.790 de 23/03/99, conhecida como Lei do Terceiro Setor, que permite estabelecer parcerias com o Governo Federal e seus órgãos no sentido de desenvolver, dentro da fundação, qualquer uma das atividades sociais, elencadas no Quadro 3, em benefício de seus associados e da comunidade, com o apoio financeiro e logístico dos órgãos públicos federais, sem qualquer finalidade lucrativa. (MENONI, 2008). 
Quadro 3 - Atividades sociais da OSCIP

\begin{tabular}{|c|l|}
\hline & \multicolumn{1}{|c|}{ Atividade social } \\
\hline I & Promoção da assistência social. \\
\hline II & Promoção da cultura, defesa e conservação do patrimônio histórico e artístico. \\
\hline III & $\begin{array}{l}\text { Promoção gratuita da educação, observando-se a forma complementar de participação das organizações } \\
\text { de que trata esta Lei. }\end{array}$ \\
\hline IV & $\begin{array}{l}\text { Promoção gratuita da saúde, observando-se a forma complementar de participação das organizações } \\
\text { de que trata esta Lei. }\end{array}$ \\
\hline V & Promoção da segurança alimentar e nutricional. \\
\hline VI & Defesa, preservação e conservação do meio ambiente e promoção do desenvolvimento sustentável. \\
\hline VII & Promoção do voluntariado. \\
\hline VIII & Promoção do desenvolvimento econômico e social e combate à pobreza. \\
\hline IX & $\begin{array}{l}\text { Experimentação, não lucrativa, de novos modelos sócios produtivos e de sistemas alternativos de } \\
\text { produção, comércio, emprego e crédito. }\end{array}$ \\
\hline X & $\begin{array}{l}\text { Promoção de direitos estabelecidos, construção de novos direitos e assessoria jurídica gratuita de } \\
\text { interesse suplementar. }\end{array}$ \\
\hline XI & $\begin{array}{l}\text { Promoção da ética, da paz, da cidadania, dos direitos humanos, da democracia e de outros valores } \\
\text { universais. }\end{array}$ \\
\hline XII & $\begin{array}{l}\text { Estudos e pesquisas, desenvolvimento de tecnologias alternativas, produção e divulgação de } \\
\text { informações e conhecimentos técnicos e científicos que digam respeito às atividades mencionadas } \\
\text { neste artigo. }\end{array}$ \\
\hline
\end{tabular}

Fonte: Menoni (2008).

A Fundação passou a integrar a Rede Parceria Social em abril de 2009, na qualidade de entidade âncora do projeto em Rede, segundo o entrevistado 4. Esse projeto tem por objetivo fornecer assessoria técnica e financeira para os projetos de inclusão social produtiva de jovens e adultos em situação de vulnerabilidade social, por meio da geração de renda através do artesanato para a inserção ao mercado de trabalho. Este projeto tem como público alvo as entidades sociais ou organizações sociais (ONG) situadas no Rio Grande do Sul, devidamente cadastradas na Secretaria do Trabalho e do Desenvolvimento Social e Conselho Municipal da Assistência Social, que atendam pessoas que se encontram em situação de vulnerabilidade social. O Projeto em Rede recebeu o Prêmio Top Ser Humano da Associação Brasileira de Recursos Humanos (ABRH-RS). (ENTREVISTADO 4).

Outro projeto de destaque chama-se de Novos Horizontes, por meio da Fundação em parceria com a Fundação Pescar, promove a sustentabilidade social e desenvolve esse projeto desde 1999. O projeto qualifica jovens em situação de vulnerabilidade social e cria oportunidades que transformam vidas através da formação profissional e do desenvolvimento social. Esta iniciativa está em consonância com a lei de formação do jovem aprendiz. Esse projeto recebeu o prêmio Top Cidadania da ABRH-RS. A sistemática desse projeto contempla,

o lançamento de edital público para as escolas, para os centros de referência, para secretaria do trabalho e desenvolvimento social, e para rede de contatos. Na seleção, os jovens preenchem uma ficha para verificar os critérios de idade, moradia, pois tem a questão de transporte. É feita uma visita domiciliar, aplicada uma prova de conhecimento, então se faz um desenvolvimento de grupo para avaliar relacionamento, se faz exame médico e assina o contrato de trabalho. Eles têm aula de controle financeiro para saber o que fazer com o dinheiro da bolsa, como utilizar e aplicar para administrar a vida. Para sustentar esse projeto, a Fundação se relaciona com o Conselho da Criança e Adolescente de Campo Bom e Novo Hamburgo (RS), através do Projeto Leão do Bem, são captados recursos de pessoas que podem doar para receita federal, 
podem ser doados de 3 a 6\% para o fundo da criança, a Fundação aprova esse projeto, capta os recursos e aplica no projeto. Com essa aplicação foi montado o laboratório de informática. Esse jovem tem aula de informática, aula de espanhol, ginástica, acesso a biblioteca, pesquisa na internet, aula de teatro, eles mesmos montaram um jornal deles, onde são divulgados assuntos da Fundação e a experiência deles. (ENTREVISTADO3).

Ainda é realizado um acompanhamento do egresso no período de dois anos. Para o entrevistado 3, "é realizado encontro dos egressos, eles comparecem na empresa, participam de um almoço, contam a história do que estão fazendo da vida, se estão estudando, alguns querem só estudar e muitos já estão empregados. Alguns são contratados pela empresa."

Outro projeto realizado pela Fundação chama-se Em Férias, o projeto teve início em 2008 e tem como objetivo despertar em crianças e adolescentes a consciência ecológica, noções de preservação da natureza e destacar a importância da sustentabilidade. O público alvo desse projeto são os filhos dos funcionários da empresa de 7 a 14 anos.

Além dos projetos destacados, outros são desenvolvidos pela Fundação para os públicos interno e externo e são apresentados no Quadro 4.

Quadro 4 - Projetos da Fundação

\begin{tabular}{|l|l|}
\hline \multicolumn{1}{|c|}{ Denominação } & \multicolumn{1}{c|}{ Descrição } \\
\hline $\begin{array}{l}\text { Projeto Educação de } \\
\text { Jovens e Adultos (EJA) }\end{array}$ & $\begin{array}{l}\text { Contribui para a socialização do conhecimento, propondo o desenvolvimento } \\
\text { pessoal e profissional dos funcionários e famílias por meio do curso de ensino } \\
\text { Fundamental e Médio. O ensino é realizado através da Educação a Distância, em } \\
\text { parceria com SESI/RS. }\end{array}$ \\
\hline $\begin{array}{l}\text { Realização de Eventos } \\
\text { Diversos - Ações de } \\
\text { Integração }\end{array}$ & $\begin{array}{l}\text { Realiza diversos eventos sociais, esportivos, culturais e campanhas de mobilização, } \\
\text { como: Festa de final de ano, Dia do Desafio, Campeonato de Futsal, Torneio do } \\
\text { SESI, Gincana da Sustentabilidade, Gincana de Decoração de Natal e o Baile da } \\
\text { Fundação. Também foram organizadas feiras de Material Escolar e Feira de Páscoa, } \\
\text { almoço de Natal, realizado em todas as unidades da empresa com distribuição de } \\
\text { brindes. }\end{array}$ \\
\hline Voluntariado & $\begin{array}{l}\text { É um programa voluntariado corporativo, que iniciou em 2010. É incentivada a } \\
\text { solidariedade dos profissionais, em programas permanentes ou pontuais. Eles se } \\
\text { envolvem em diferentes atividades que buscam a promoção humana e o bem estar } \\
\text { social. }\end{array}$ \\
\hline $\begin{array}{l}\text { Projeto de Inclusão } \\
\text { Digital }\end{array}$ & $\begin{array}{l}\text { Funcionários e familiares participam desse projeto, são oferecidos cinco cursos em } \\
\text { parceria com o SESI, sobre Windows, Word, Excel básico e Excel. }\end{array}$ \\
\hline Centro Conviver & $\begin{array}{l}\text { Possui espaço especial para a convivência e para o lazer dos funcionários, com } \\
\text { uma ampla biblioteca com livros, revistas e periódicos. Os funcionários possuem } \\
\text { um espaço para descanso nas horas de intervalo. }\end{array}$ \\
\hline Outros serviços & $\begin{array}{l}\text { Financia empréstimos, realiza cursos de informática, espanhol e violão para os } \\
\text { funcionários. Tem parcerias com o SESI para acesso a cultura, torneios esportivos, } \\
\text { aulas de ginástica. Apoia grupos de corrida de funcionários que participam de } \\
\text { maratonas. }\end{array}$ \\
\hline Escola & $\begin{array}{l}\text { A empresa participa das atividades dessa escola municipal que beneficia cerca de } \\
800 \text { alunos, que leva o nome do seu fundador, e situa-se em Novo Hamburgo - RS. }\end{array}$ \\
\hline
\end{tabular}

Fonte: Elaboração própria com base nos dados.

As ações gerenciadas pela Fundação contemplam a inclusão social que integra as pessoas que vivem na comunidade, incentiva a solidariedade e promove a educação (projeto em rede, projeto educação de jovens e adultos, escola, projeto novos horizontes, projeto em férias); a inclusão digital 
que compreende ações de difusão de conhecimento por meio do uso de computadores, domínio da informática básica (projeto inclusão digital); inclusão econômica por meio da geração de empregos e rendas e estímulo ao empreendedorismo (projeto em rede, projeto novos horizontes); inclusão cultural que incentiva à preservação do patrimônio físico e histórico da empresa. (MELO NETO; FROES, 2011). Assim, verifica-se que ações do pilar social permitem diversas formas de inclusão e a empresa assume o seu papel de agente indutor desse processo.

Além das atividades e programas coordenados pela Fundação, outra área responsável pelo gerenciamento de ações sociais para o público interno é chamada de Desenvolvimento Organizacional, que tem como objetivo consolidar a diretriz estratégica "desenvolvimento de pessoas".

Para isso foi criada a Universidade Corporativa que visa promover a excelência na gestão e a inovação por meio da valorização das pessoas, do desenvolvimento do pensamento sistêmico, da liderança estratégica, da visão de futuro e da geração de valor, isto ocorre por meio de programas de desenvolvimento de pessoas coordenados pela área de Desenvolvimento Organizacional. (ENTREVISTADO 4).

Quadro 5 - Atividades para o Público Interno - Desenvolvimento Organizacional

\begin{tabular}{|c|c|}
\hline Projeto & Descrição \\
\hline $\begin{array}{l}\text { Programa de } \\
\text { Integração de Novos } \\
\text { Funcionários }\end{array}$ & $\begin{array}{l}\text { Este programa é desenvolvido com todos os novos funcionários, seu objetivo é } \\
\text { apresentar a empresa, suas unidades de negócio, seus produtos, planos de benefícios e } \\
\text { os programas que são desenvolvidos internamente. }\end{array}$ \\
\hline $\begin{array}{l}\text { Programa Gestão de } \\
\text { Performance }\end{array}$ & $\begin{array}{l}\text { O programa visa estabelecer uma sistemática e regras para mensurar as metas e as } \\
\text { competências de cada funcionário, através do Contrato de Metas. O foco é alinhar } \\
\text { os funcionários ao negócio e às suas intenções estratégicas, construir lucro líquido } \\
\text { que permita que os negócios cresçam com sustentabilidade, melhorar a eficiência dos } \\
\text { resultados com sustentabilidade e acelerar a performance do negócio e das pessoas. } \\
\text { Os funcionários são avaliados pelo programa de Gestão de Performance, com análise } \\
\text { de metas quantitativas e qualitativas. As qualitativas compreendem as competências, } \\
\text { enquanto as quantitativas envolvem indicadores numéricos relacionados à estratégia } \\
\text { do negócio. Nas qualitativas, o processo ocorre através da avaliação } 180^{\circ} \text { e } 360^{\circ} \text {. O } \\
\text { programa gestão de performance abrange } 100 \% \text { dos funcionários e está atrelado ao } \\
\text { plano de participação nos resultados. }\end{array}$ \\
\hline $\begin{array}{l}\text { Programa de } \\
\text { Desenvolvimento de } \\
\text { Competências }\end{array}$ & $\begin{array}{l}\text { Tem como objetivo capacitar novos talentos, desenvolvendo competências técnicas } \\
\text { e comportamentais, para agregar valor ao próprio indivíduo e colaborar com o } \\
\text { atingimento da intenção estratégica. O programa abrange atividades como: elaboração } \\
\text { do plano de estágio, relatório trimestral de acompanhamento do plano de estágio, } \\
\text { avaliação de desempenho trimestral e trabalho de conclusão. }\end{array}$ \\
\hline $\begin{array}{l}\text { Programa Conversa } \\
\text { com o Presidente }\end{array}$ & $\begin{array}{l}\text { Oportuniza que os funcionários, através de uma roda de chimarrão, troquem ideias } \\
\text { com o Presidente. }\end{array}$ \\
\hline $\begin{array}{l}\text { Programa de } \\
\text { Desenvolvimento de } \\
\text { Dirigentes }\end{array}$ & Programa voltado para o desenvolvimento da equipe diretiva. \\
\hline
\end{tabular}




\begin{tabular}{|c|c|}
\hline $\begin{array}{l}\text { Programa Líderes } \\
\text { do Futuro }\end{array}$ & $\begin{array}{l}\text { Este programa tem como objetivo desenvolver lideranças para sustentar os objetivos } \\
\text { estratégicos da empresa, tornando-a uma empresa de alta performance. Dentro desse } \\
\text { conceito, são desenvolvidos dois programas de formação de lideranças: (a) Programa } \\
\text { Fábrica de Líderes que tem como objetivo preparar os funcionários que não possuem } \\
\text { função de líder para ocupar posição de liderança; (b) Programa Gestores Básicos, com } \\
\text { foco no aperfeiçoamento dos líderes, o programa consiste em módulos que abordam } \\
\text { administração de conflitos, desenvolvimento de equipe, gestão da inovação, gestão da } \\
\text { rotina e avaliação de desempenho. }\end{array}$ \\
\hline $\begin{array}{l}\text { Programa Boas- } \\
\text { Vindas }\end{array}$ & $\begin{array}{l}\text { Trata-se do primeiro evento do ano realizado no mês de janeiro de cada ano para } 100 \% \\
\text { dos funcionários. Tem como objetivo direcionar e comunicar as intenções estratégicas, } \\
\text { apresentar informações relevantes da empresa como os resultados obtidos no ano } \\
\text { anterior e os novos objetivos para o ano corrente. Essas informações são apresentadas } \\
\text { pelo Presidente e pelos gestores. }\end{array}$ \\
\hline Programa Equipe & $\begin{array}{l}\text { Busca o desenvolvimento grupal visando à formação de equipes de trabalho integradas, } \\
\text { comprometidas, inovadoras e focadas na construção dos resultados. A realização } \\
\text { deste programa deve partir da necessidade do gestor ou da equipe, pois parte-se } \\
\text { do pressuposto de que os participantes devem ter disponibilidade para mudaça de } \\
\text { comportamento. }\end{array}$ \\
\hline $\begin{array}{l}\text { Programa Equipes } \\
\text { de Alta Performance }\end{array}$ & $\begin{array}{l}\text { Visa desenvolver nos participantes as competências comportamentais que contribuirão } \\
\text { na melhoria da performance individual e grupal. Este programa é realizado pelos } \\
\text { diretores e seu grupo direto de trabalho. O primeiro módulo aborda o autoconhecimento, } \\
\text { o segundo reforça os vínculos entre as pessoas, e o terceiro foca a superação. }\end{array}$ \\
\hline $\begin{array}{l}\text { Programa de } \\
\text { Educação a } \\
\text { Distância }\end{array}$ & $\begin{array}{l}\text { A educação à distância (EAD) oportuniza o conhecimento e o desenvolvimento dos } \\
\text { funcionários. }\end{array}$ \\
\hline Pesquisa de Clima & $\begin{array}{l}\text { Esta ferramenta tem como objetivo avaliar o clima organizacional, os apontamentos } \\
\text { apresentados são tratados pela diretoria e pelos gestores, para melhorar a performance } \\
\text { organizacional. }\end{array}$ \\
\hline Benefícios & $\begin{array}{l}\text { A empresa possui um pacote de benefícios aplicados, corporativamente ou de acordo } \\
\text { com as necessidades de cada unidade em conformidade com a legislação vigente do } \\
\text { país ou região em que estão sendo aplicados. }\end{array}$ \\
\hline $\begin{array}{l}\text { Plano de Cargos e } \\
\text { Salários }\end{array}$ & $\begin{array}{l}\text { O plano visa atrair e reter os funcionários com as competências necessárias ao negócio, } \\
\text { remunerando de acordo com as práticas e as tendências de mercado. }\end{array}$ \\
\hline $\begin{array}{l}\text { Programa de } \\
\text { Participação dos } \\
\text { Resultados (PRA) }\end{array}$ & $\begin{array}{l}\text { A PRA está alinhada ao planejamento estratégico da empresa no qual busca não } \\
\text { apenas atingir metas, mas principalmente superá-las. Este programa serve como fator } \\
\text { motivacional junto aos funcionários e os retribui pelos resultados superados entre o } \\
\text { orçamento e o realizado. }\end{array}$ \\
\hline $\begin{array}{l}\text { Programa de } \\
\text { Reconhecimento }\end{array}$ & $\begin{array}{l}\text { A empresa presta homenagem aos funcionários com maior tempo de trabalho. É } \\
\text { promovida anualmente, com o destaque aos laureados. Todo ano ocorre um evento, } \\
\text { com almoço festivo, em que os funcionários que completam } 5,10,15 \text { e } 20 \text { anos ou } \\
\text { mais de empresa são homenageados. Para aqueles que são jubilados, é feita uma } \\
\text { distinção com entrega de troféus. }\end{array}$ \\
\hline $\begin{array}{l}\text { Comunicação } \\
\text { Interna }\end{array}$ & $\begin{array}{l}\text { É através da comunicação interna que a empresa compartilha sua cultura e estimula a } \\
\text { troca de informações entre os funcionários, são utilizados vários canais de comunicação } \\
\text { para disponibilizar as informações para todos os funcionários. Para isso, a empresa } \\
\text { tem uma área de endomarketing. }\end{array}$ \\
\hline
\end{tabular}




\begin{tabular}{|l|l|}
\hline $\begin{array}{l}\text { Segurança e Saúde } \\
\text { no Trabalho }\end{array}$ & $\begin{array}{l}\text { Foram realizadas várias campanhas, tais como: bom dia segurança: ferramenta de } \\
\text { informação em que são ministrados, diária ou semanalmente, assuntos que abordam } \\
\text { segurança, saúde e meio ambiente; campanha pratique prevenção - relato de perigo: } \\
\text { criada com o objetivo de antecipar os riscos, todo o funcionário pode relatar atos } \\
\text { e condições inseguras no formulário padrão, onde os relatos serão avaliados e } \\
\text { evidenciados; campanha carnaval: cuidados com bebidas e trânsito e campanha contra } \\
\text { a AIDS; palestra de prevenção ao câncer de mama; semana nacional de segurança } \\
\text { no trânsito; alerta segurança final de ano: campanha relacionando segurança no } \\
\text { trânsito e cuidados necessários para o período de férias; palestra sobre mecânica } \\
\text { básica automotiva para mulheres, com foco em rodas e pneus; grupo de atendimento } \\
\text { de emergência: funcionários que recebem treinamento teórico e prático para agir } \\
\text { em situações de emergência; semana interna de prevenção de acidentes de trabalho; } \\
\text { palestra sobre primeiros socorros. }\end{array}$ \\
\hline
\end{tabular}

Fonte: Elaborado própria com base no Relatório de Sustentabilidade e dados das entrevistas.

As ações gerenciadas pela área de Desenvolvimento Organizacional demostram a responsabilidade pelo bem-estar de seus funcionários. (FARIA; PEREIRA, 2009). A valorização das pessoas está entre os principais fatores que se refletem nos bons resultados de uma organização. (PORTER; KRAMER, 2006). Pode-se verificar que as ações com foco no público interno não se restringem apenas ao pagamento de salários e a concessão de benefícios obrigatórios por lei. (TENÓRIO, 2004; YUNUS, 2008; MELO NETO; FROES, 2011). O modo como às pessoas são tratadas influenciam no crescimento e na sustentabilidade da organização. (ASPINALL; CUKIER; DOBERSTEIN, 2011).

Além dos projetos e programas desenvolvidos para os públicos interno e externo da empresa apresentados nos Quadros 4 e 5, a empresa também investe em produtos que agregam o pilar social coordenados pela área de Tecnologia. Segundo o entrevistado 1, "algumas tecnologias desenvolvidas através das nossas operações oferecem ganhos não apenas ambientais, mas sociais, pela facilidade de aplicação da tecnologia". O entrevistado 1 ressalta que "a empresa apenas produz linhas de adesivos que podem conter uma porcentagem de solventes orgânicos, regulamentados conforme a Norma Brasileira NR 15 e pela Divisão de Controle de Produtos Químicos pela Polícia Federal”.

O entrevistado 2 reforça que "a empresa possui um canal de relacionamento com os clientes para esclarecimento de dúvidas através da equipe de representantes e técnicos, seja por visitas, e-mail e/ou telefone". Diz ainda que "a NR15 está relacionada com as atividades e operações insalubres, que trata dos agentes químicos cuja insalubridade é caracterizada por limite de tolerância e inspeção no local de trabalho". Desse modo, "não são comercializados produtos proibidos ou contestados no mercado.” (ENTREVISTADO 3).

A cadeia de fornecedores da empresa é formada por empresas multinacionais. Os fornecedores estão segmentados em três grupos: matérias-primas, insumos e serviços. Os fornecedores de matériasprimas representam $80 \%$ do montante de compras e pertencem, em sua maioria, ao segmento petroquímico, fornecendo principalmente resinas, solventes, monômeros, borrachas e não tecidos. Atualmente $75 \%$ das matérias-primas utilizadas na produção são adquiridas no mercado interno. Os outros 25\% são importadas, principalmente da Ásia, Europa e Estados Unidos. Além disso, na matriz são centralizadas todas as negociações globais com os principais fornecedores que atendem não somente Brasil, como também as filiais na América Latina. (RELATÓRIO DE SUSTENTABILIDADE, 2018). Conforme o entrevistado 2,

todos os fornecedores de matérias-primas, ou seja, $100 \%$ deles, respondem a um questionário que contempla aspectos de saúde, segurança, meio ambiente e compromisso com a sociedade. As questões abordam certificações ambientais, trabalhistas e sociais, plano de emergência 
ambiental, sistemas de monitoramento com metas específicas para redução do consumo de água, geração de resíduos, de combustíveis fósseis e energia elétrica, controle do uso de equipamentos de proteção individual (EPI's), e de equipamentos com dispositivos de segurança para proteção dos operadores, entre outros.

Um exemplo de produto que agrega a questão social e a sustentabilidade é a linha ecofibra, "produzida pela empresa para diferentes mercados, principalmente automotivo e calçadista." (ENTREVISTADO2).

\footnotetext{
O produto é um laminado termoplástico com fibra vegetal em sua composição. Em geral, produtos similares são $100 \%$ produzidos a partir de polímeros de origem petroquímica, uma fonte não-renovável. A linha ecofibra reduz o consumo de matéria-prima de fonte não renovável e ainda utiliza resíduos de outros setores como matéria-prima, uma vez que a fibra vegetal pode ser bagaço de cana-de- açúcar (indústria sucro-alcooleira), pó de madeira (indústrias que atuam com madeira), fibra de coco e acerola (sobras da indústria alimentícia), entre outras possibilidades. (ENTREVISTADO 1).
}

Segundo o entrevistado 1 é possível observar os impactos ecossociais da ecofibra na produção de carros da GM fabricados no Brasil. Um porta-pacotes foi desenvolvido e permitiu a homologação da empresa alvo do estudo como fornecedora mundial da montadora. Além disso, para produzir o porta-pacotes foram utilizadas cerca de 100 toneladas de fibras vegetais que eram resíduos de outras indústrias e que foram transformados em matéria-prima ecofibra que pode ser $100 \%$ reciclado, com reaproveitamento do material direto na conformação de novas peças, sem necessidade de novos processos de transformação.

Algumas vantagens dos produtos ecossociais são: menor emissão de $\mathrm{CO}^{2}$; solução para a gestão de resíduos sólidos; o produto oferece ganhos econômicos, pois apresenta melhor performance, melhor relação custo $\mathrm{x}$ benefício, ganhos de processo no cliente e forte impacto na rentabilidade da empresa. A parte interna do veículo produzida com ecofibra (porta-pacotes) reduz o peso dos veículos em 0,4 kg. (RELATÓRIO DE SUSTENTABILIDADE, 2018).

A partir dos dados averígua-se a relevância da área de tecnologia no gerenciamento de ações que apresentam contribuições sociais. O desenvolvimento de produtos com foco nas estratégias de sustentabilidade e alinhados com os valores organizacionais melhoram a imagem da empresa para os públicos interno e externo. (AMORIM, 2009; ALIGLERI; ALIGLERI; KRUGLIANSKAS, 2009).

Esta seção apresentou as ações que contemplam o pilar social da sustentabilidade empresarial na empresa alvo do estudo. A seguir é abordada uma síntese dos resultados e as discussões da pesquisa.

\section{RESULTADOS E DISCUSSÕES}

Este artigo buscou verificar as ações que contemplam o pilar social da sustentabilidade empresarial em uma empresa do segmento químico. A partir da descrição dos dados pode-se verificar que a empresa investe em ações que contemplam o pilar social da sustentabilidade empresarial. Essas ações são coordenadas por três áreas: a) Fundação, foco no público interno e comunidades; b) Desenvolvimento Organizacional, foco no público interno; c) Tecnologia, foco no desenvolvimento de produtos chamados ecossociais. O Quadro 6 apresenta a síntese das ações identificadas. 
Quadro 6 - Síntese das Ações Sociais

\begin{tabular}{|l|l|l|}
\hline \multicolumn{1}{|c|}{ Coordenação } & \multicolumn{1}{|c|}{ Objetivo } & \multicolumn{1}{c|}{ Ações } \\
\hline Fundação & $\begin{array}{l}\text { Promover a educação por } \\
\text { meio de processos sócios } \\
\text { educativos. }\end{array}$ & $\begin{array}{l}\text { Projeto em Rede, Novos Horizontes, Inclusão Digital, } \\
\text { Educação de Jovens e Adultos, Escola Municipal, Em } \\
\text { Férias, Voluntariado, Centro Conviver, outros serviços. }\end{array}$ \\
\hline $\begin{array}{l}\text { Desenvolvimento } \\
\text { Organizacional }\end{array}$ & $\begin{array}{l}\text { Desenvolver ações que } \\
\text { visam o desenvolvimento } \\
\text { e o bem-estar dos } \\
\text { colaboradores. }\end{array}$ & $\begin{array}{l}\text { Programa de Integração, Programa Gestão de } \\
\text { Performance, Programa de Desenvolvimento de } \\
\text { Competências, Programa Conversa com o Presidente } \\
\text { Programa de Desenvolvimento de Dirigentes, Programa } \\
\text { Líderes do Futuro, Programa Boas-Vindas, Programa } \\
\text { Equipe, Programa Equipes de Alta Performance, } \\
\text { Programa de Educação a Distância, Pesquisa de Clima, } \\
\text { Benefícios, Plano de Cargos e Salários, Programa de } \\
\text { Participação dos Resultados, Promoções Internas, } \\
\text { Programa de Reconhecimento, Comunicação Interna, } \\
\text { Segurança e Saúde no Trabalho. }\end{array}$ \\
\hline Tecnologia & $\begin{array}{l}\text { Eliminação de toxicidade dos adesivos; uso de solventes } \\
\text { orgânicos, quando necessário; desenvolvimento da } \\
\text { que facilitam a vida das } \\
\text { pessoas e que contribuem } \\
\text { para melhora da qualidade } \\
\text { de vida. }\end{array}$ & \\
\hline
\end{tabular}

Fonte: Elaboração Própria.

A partir dos dados apresentados no Quadro 6, pode-se afirmar que a empresa em estudo realiza ações sociais que envolvem os stakeholders da empresa, com ênfase nos dirigentes, colaboradores, comunidades, fornecedores e clientes. Essas ações corroboram com os conceitos apresentados pelos autores Elkington (1997); Coral (2002); Catalisa (2003); Werbach (2010); Littlejohns \& Smith (2013). Diante disso, pode-se dizer que a adoção de princípios de sustentabilidade leva ao desenvolvimento de uma cultura organizacional orientada à sustentabilidade. (LINNENLUECKE; GRIFFITHS, 2016).

De modo geral, os aspectos geralmente contemplados no pilar social no contexto empresarial são: segurança no trabalho, saúde preventiva, ambiente limpo e seguro, ambiente de trabalho que favoreça a produtividade, adequação às leis trabalhistas, campanhas e programas socioambientais, formação de pessoas e lideranças, benefícios adicionais aos estabelecidos por lei, incentivo à educação dos funcionários, realização de programas de integração entre empresa e comunidade, etc. (FROEHLICH, 2014). Esses aspectos foram constatados no caso apresentado, pode-se acrescentar a ação de desenvolvimento de produtos que facilitam a vida das pessoas e que contribuem para melhora da qualidade de vida (ecossociais).

Ainda constatou-se que a sustentabilidade está inserida na missão, visão e valores organizacionais, essa prática é apontada por Galpin \& Whittington (2012) como uma forma de construção da marca orientada para sustentabilidade. Desse modo, as ações sociais gerenciadas pelas três áreas da empresa buscam complementar e contribuir para consolidação das estratégias de sustentabilidade da organização. Assim, induz a um novo modelo de gestão de negócios que observa os pilares econômico, ambiental e social nas tomadas de decisões. (CHRISTOFI; CHRISTOFI; SISAYE, 2012; PHILLIP JR.; SAMPAIO; FERNANDES, 2017). Para empresa desse estudo, a ação social é considerada uma função estratégica conforme destacam Melo Neto \& Froes (2004). Com isso, é possível dizer que a valorização das pessoas está entre os principais fatores que se refletem na vantagem competitiva da organização. (PORTER; KRAMER, 2006).

Os desempenhos das ações sociais são mensurados e divulgados para sociedade por meio do Balanço Social (publicado até 2013) e do Relatório de Sustentabilidade (publicado a partir de 2014). Analisar as ações sociais oportuniza avaliar o desempenho sustentável. (AMORIM, 2009; ALIGLERI; ALIGLERI; KRUGLIANSKAS, 2009; FERNANDES; FONSECA; CUNHA, 2018). 


\section{CONSIDERAÇÕES FINAIS}

Para responder a questão de pesquisa “Quais são as ações sociais que constituem a sustentabilidade empresarial em uma organização do segmento químico?”, este estudo teve como objetivo verificar as ações que contemplam o pilar social da sustentabilidade empresarial em uma indústria do segmento químico, situada na Região do Vale do Rio dos Sinos, no Rio Grande do Sul.

Pode-se concluir que a empresa realiza e desenvolve ações sociais que contribuem para a sustentabilidade empresarial, conforme mostrou o Quadro 6, no item sobre resultados e discussões. Ainda, as ações sociais identificadas buscam complementar e contribuir para consolidação das estratégias de sustentabilidade da organização.

Esse estudo apresentou como contribuição empírica, as ações que contemplam opilar social da sustentabilidade empresarial a partir de um estudo de caso; e as áreas responsáveis pela coordenação para desdobrar as estratégias de sustentabilidade em práticas, que são: Fundação; Desenvolvimento Organizacional; e Tecnologia.

Pode-se destacar como limitação, que o estudo realizado não pode ser generalizado, pois trata de um estudo de caso único, com base na percepção dos próprios colaboradores do caso investigado. Ainda, a pesquisa teve como foco a análise do ambiente interno, não contemplando os demais stakeholders como clientes e fornecedores, que poderiam contribuir para ampliar os resultados do estudo.

Para novos estudos, sugere-se uma pesquisa quantitativa com todos os funcionários para verificar se as ações sociais de sustentabilidade realizadas são percebidas. Também uma pesquisa com os stakeholders externos para verificar como percebem as ações sociais de sustentabilidade e como poderiam contribuir para otimização das mesmas.

\section{REFERÊNCIAS}

ALIGLERI, L.; ALIGLERI, L. A.; KRUGLIANSKAS, I. Gestão socioambiental: responsabilidade e sustentabilidade do negócio. São Paulo: Atlas, 2009.

AMORIM, T. Responsabilidade social corporativa. In: ALBUQUERQUE, J. L. (org.). Gestão ambiental e responsabilidade social: conceitos, ferramentas e aplicações. São Paulo: Atlas, 2009.

ANDINO, B. F. A. Proposta de uma estrutura analítica para a identificação do perfil de sustentabilidade de cadeias de suprimentos. Tese (Doutorado em Administração)- Escola de Administração, Universidade Federal do Rio Grande do Sul, Porto Alegre, 2011.

ASPINALL, A.; CUKIER, J.; DOBERSTEIN, B. Quality of life assessments and social sustainability: Ski Tourism development in Invermere, British Columbia. Journal of Environmental Assessment Policy and Management, v.13, n.2, p.179-201, jun.2011

BARBIERI, J. C.; CAJAZEIRA, J. E. R. Responsabilidade social empresarial e empresa sustentável: da teoria à prática. São Paulo: Saraiva, 2009.

BARDIN, L. Análise de conteúdo. Lisboa: Edições 70, 2010.

BELL, S.; MORSE, S. Sustainability indicators: measuring the immeasurable?. 2. ed. London: Earthscan, 2008. 
BOSSEL, H. Indicators for sustainable development: theory, method, applications. Canada: International Institute for Sustainable Development, 1999.

CARROL, Archie B. The pyramid of corporate social responsibility: toward the moral management of organizational stakeholders. Business Horizons, v.34, n.4, p.39-48, jul./aug., 1991.

CHRISTOFI, A.; CHRISTOFI, P.; SISAYE, S. Corporate sustainability: historical development and reporting practices. Management Research Review, v. 35, n. 2, p. 157-172, 2012.

CATALISA. Rede de cooperação para a sustentabilidade. 2003. Disponível em: http://www. catalisa.org.br/content/view/30/59/. Acesso em: 12 fev. 2018.

CORAL, E. Modelo de planejamento estratégico para a sustentabilidade empresarial. Tese (Doutorado em Engenharia de Produção) - Centro Tecnológico, Universidade Federal de Santa Catarina, Florianópolis, SC, 2002.

ELKINGTON, J. Cannibals with forks: the triple bottom line of $21^{\text {st }}$ century business. Capstone Publishing: Oxford, 1997.

ENGERT, S.; RAUTER, R.; BAUMGARTNER, R. J. Exploring the integration of corporate sustainability into strategic management: a literature review. Journal of Cleaner Production, 112, p. 2833-2850, 2016.

FARIA, A. C.; PEREIRA, R. S. Disclosure de informações socioambientais pelas maiores empresas do segmento químico e petroquímico no Brasil, a partir da NBC T -15. In: XXXIII ENCONTRO DA ANPAD. 2009, São Paulo. Anais [...]. São Paulo: USP, 2009.

FERNANDES, A. R. de J.; FONSECA, S. E.; CUNHA, C. L. Responsabilidade Social e Influências sobre Retornos de Cotações: Um Estudo Acerca do Desempenho de Índices de Sustentabilidade. Revista Administração em Diálogo - Rad, São Paulo, v. 20, n. 1, p.25-39, jan. 2018.

FLICK, U. Uma introdução à pesquisa qualitativa. 2. ed. Porto Alegre: Bookman, 2004.

FROEHLICH, C. O desenvolvimento da capacidade de inovação para alavancar a sustentabilidade empresarial. Tese (Doutorado em Administração) - Programa de Pós-Graduação em Administração, Universidade do Vale do Rio dos Sinos - Unisinos., São Leopoldo, RS, 2014.

GALPIN, T.; WHITTINGTON, J. L. Sustainability leadership: from strategy to results. Journal of Business Strategy, v. 33, n. 4, p. 40-48, 2012.

GLADWIN, T. N.; KRAUSE, T.; KENNELLY, J. Eco-efficiency: toward socially sustainable business. Sustainable Development, v.3, p. 35-43, 1995.

JIMÉNEZ HERRERO, L. Desarrollo sostenible: transición hacia la coevolución global. Madrid: Pirámide, 2000. 
JORDÃO, V. D. et al. Estratégia e sustentabilidade socioambiental: um estudo empírico das empresas listadas no índice de sustentabilidade empresarial da BM\&Fbovespa. In: SEMINÁRIO DE ADMINISTRAÇÃO DA USP - SEMEAD. Anais [...]. São Paulo: USP, 2009.

LAFFERTY, W. M.; MEADWCROFT, J. Implementing sustainable development.UK: Oxford University Press, 2000.

LINNENLUECKE, M. K.; GRIFFITHS, A. Corporate sustainability and organizational culture. Journal of World Business, v. 45, p. 357-366, 2010.

LITTLEJOHNS, L. B.; SMITH, N. Building bridges between health promotion and social sustainability: an analysis of municipal policies in Western Canada. Local Environment, v. 19, n. 4, p. 449-468, 2013.

MELO NETO, F.; FROES, C. O bem-feito: os novos desafios da gestão da responsabilidade socioambiental sustentável corporativa. Rio de Janeiro: Qualitymark, 2011.

MELO NETO, F.; FROES, C. Gestão da responsabilidade social corporativa: o caso brasileiro. 2. ed. Rio de Janeiro: Qualitymark, 2004.

MENONI, J. Livro institucional. Porto Alegre: Algo Mais Editora, 2008.

MOZAFFAR, K.; SERAFEIM, G.; YOON, A. Corporate sustainability: first evidence on materiality. Harvard Business School, Reino Unido, n. 15-073, mar. 2015.

PHILIPI JR, A.; SAMPAIO, C.A. C.; FERNANDES, V. Gestão empresarial e sustentabilidade. Barueri, SP: Manole, 2017.

PORTER, M. E.; KRAMER, M. R. Strategy e society: the link between competitive advantage and corporate social responsibility. Harvard Business Review, p. 1-15, dec., 2006.

RELATÓRIO DE SUSTENTABILIDADE EMPRESARIAL. Campo Bom, RS: 2018.

SACHS, I. Estratégias de transição para o século XXI: desenvolvimento e meio ambiente. São Paulo: Fundap, 1993.

SAVITZ, A. W.; WEBER, K. A empresa sustentável: o verdadeiro sucesso é o lucro com responsabilidade social e ambiental. Rio de Janeiro: Elsevier, 2007.

SEARCY, C. Corporate sustainability performance measurement systems: a review and research agenda. Journal of Business Ethics, n. 107, p. 239-253, 2012.

SEBASTIAN, J. Metodología para la evalución ex-post de programas de fomento a La innovación. In: SIMPÓSIO DE GESTÃO DA INOVAÇÃO TECNOLÓGICA. Anais [...]. São Paulo: USP, 2000 . 
SIERDOVSKI, M.; STEFANO, S. R.; ANDRADE, S. M. Elementos do pilar social da sustentabilidade organizacional: um estudo sobre as práticas nas 150 melhores empresas para se trabalhar no Brasil. XLII Encontro da ANPAD. Anais [...]. Curitiba, PR, 2018.

SOUZA FILHO, T. A. S. et al. Sustentabilidade Socioambiental e os Stakes na Cadeia Produtiva da Castanha-da-Amazônia. In: XXXVIII ENCONTRO DA ANPAD, 2014, Porto Alegre, Anais [...] Porto Alegre, UFRGS, 2014.

TENÓRIO, F. G. Responsabilidade social empresarial. Rio de Janeiro: FGV, 2004.

VAN MARREWIJK, M. Concepts and definitions of CRS and corporate sustainability: between agency and communion. Journal of Business Ethics, v. 44, p. 95-105, 2003.

WERBACH, A. Estratégia para sustentabilidade: uma nova forma de planejar sua estratégia empresarial. Rio de Janeiro: Elsevier, 2010.

WILLARD, B. Como fazer a empresa lucrar com sustentabilidade. São Paulo: Saraiva, 2014. WORLD COMMISSION ON ENVIRONMENT AND DEVELOPMENT - WCED. Our common future. Oxford: Oxford University Press, 1987.

YIN, R. K. Estudo de caso: planejamento e métodos. 2. ed. Porto Alegre: Bookman, 2005.

YUNUS, M. Um mundo sem pobreza: a empresa social e o futuro do capitalismo. São Paulo: Ática, 2008. 